CLINICAL STUDY

\title{
Relationships between serum adiponectin levels versus bone mineral density, bone metabolic markers, and vertebral fractures in type 2 diabetes mellitus
}

Ippei Kanazawa, Toru Yamaguchi, Masahiro Yamamoto, Mika Yamauchi, Shozo Yano and Toshitsugu Sugimoto Department of Internal Medicine 1, Shimane University School of Medicine, 89-1 Enya-cho, Izumo, Shimane 693-8501, Japan

(Correspondence should be addressed to T Yamaguchi; Email: yamaguch@med.shimane-u.ac.jp)

\begin{abstract}
Background: Although, adiponectin might be associated with bone metabolism, the relationships between serum adiponectin and bone mineral density (BMD) as well as vertebral fracture in type 2 diabetes are still unclear.

Objective and methods: We investigated the relationships between each of serum total and high molecular weight (HMW) adiponectin versus BMD, bone markers, and the presence of vertebral fractures in a total of 231 men and 170 post-menopausal women with type 2 diabetes.

Results: Multiple regression analysis adjusted for age, duration of diabetes, BMI, serum creatinine, and $\mathrm{HbA}_{1 \mathrm{c}}$ showed that serum total adiponectin was negatively correlated with BMD at the total, lumbar spine, and femoral neck $(r=-0.165, P<0.05 ; r=-0.187, P<0.05$; and $r=-0.136, P<0.05$ respectively) and positively with urinary $\mathrm{N}$-terminal cross-linked telopeptide of type-I collagen in men $(r=0.148, P<0.05)$, and that serum HMW adiponectin was negatively correlated with BMD at the lumbar spine $(r=-0.146, P<0.05)$. Multivariate logistic regression analysis adjusted for the parameters described above showed that total adiponectin was associated with the presence of vertebral fractures in men (odds ratio $(\mathrm{OR})=1.396,95 \%$ confidential interval $(\mathrm{CI}) 1.020-1.911$ per S.D. increase, $P<0.05$ ), and both total and HMW adiponectin were associated with moderate or severe vertebral fractures $(\mathrm{OR}=1.709,95 \% \mathrm{CI} 1.048-2.787$ per s.D. increase, $P<0.05$ and $\mathrm{OR}=1.810,95 \%$ CI 1.112-2.946 per S.D. increase, $P<0.05$ respectively), but not in post-menopausal women.

Conclusions: Serum adiponectin could be associated with BMD and turnover and clinically useful for assessing the risk of vertebral fractures in type 2 diabetic men.
\end{abstract}

European Journal of Endocrinology 160 265-273

\section{Introduction}

Cumulative evidence has shown that there is a positive correlation between bone mineral density (BMD) and fat mass, suggesting that body fat and bone mass are related to each other (1-3). Several studies on adipocyte function have revealed that not only is adipose tissue an energy-storing organ but that it also secretes a variety of biologically active molecules, which are named adipocytokines (4). Adiponectin is one of the adipocytokines specifically and highly expressed in visceral, s.c. and bone marrow fat depots (5). It is also abundantly present in plasma (6) and has been proposed to play important roles in the regulation of energy homeostasis and insulin sensitivity $(7,8)$. We and other researchers have shown that osteoblasts have an adiponectin receptor and that the proliferation, differentiation and mineralization of osteoblastic cells are enhanced by adiponectin, suggesting that adiponectin could also influence bone metabolism $(9,10)$.
Several clinical studies have shown that serum adiponectin level was negatively correlated with BMD (11-15), while others showed no significant correlation (16-19) or a positive correlation with BMD (20). On the other hand, it is still unclear whether or not serum adiponectin level is associated with bone fractures, although one cohort study showed no significant correlation between serum adiponectin and fracture risk (21). Thus, the relationships of serum adiponectin with BMD and vertebral fractures need to be clarified further to solve the discrepancy and the lack of data respectively.

Although patients with type 2 diabetes show no apparent bone mass reduction compared with nondiabetic subjects, their fracture risks are known to increase approximately 1.5 -fold at the hip, proximal humerus, forearm, and foot (22-25). On the other hand, two large-scale studies have shown that a risk for vertebral fractures was not significantly higher in patients with type 2 diabetes than in those without 
diabetes $(22,23)$. However, we found that lumbar BMD was not associated with the presence of vertebral fractures in the group, suggesting the insensitiveness of BMD to assess their fracture risk (26). Thus, sarrogate markers that supplement BMD and detect the fracture presence are required. We have recently shown that serum insulin-like growth factor-1 and pentosidine levels could be clinically useful for assessing the risk of vertebral fractures independent of BMD in postmenopausal women with type 2 diabetes $(27,28)$. However, we found that these parameters were not effective in the male counterpart, and thus some other biochemical markers are needed to assess the fracture risk in them.

Serum adiponectin may be a potential candidate for assessing the risk of vertebral fractures in diabetic men. Lenchik et al. showed that adiponectin exerted an independent negative correlation with BMD in subjects including 86\% with type 2 diabetes (11). By contrast, Tamura et al. showed that adiponectin was positively correlated with BMD at the radius in diabetic patients (20). The discrepancy between the two studies might be partly because they lumped men and women together, although serum adiponectin concentration is known to be different between the sexes $(29,30)$.

Recently, the difference in molecular weight of adiponectin is known to be important for its function. Adiponectin exists in the circulation as a trimer (low molecular weight (LMW)), a hexamer (medium molecular weight (MMW)), and a high molecular weight (HMW) form. Previous study showed that only HMW adiponectin could induce activation of AMP-activated protein kinase (AMPK) in hepatocytes, while both total and HMW adiponectin could activate AMPK in myocytes (30). On the other hand, some investigators have indicated that LMW and HMW adiponectin activated different signal transduction pathways via changes in its oligomerization state (31). Thus, biological activities among these isoforms of adiponectin are still unclear, especially in bone cells.

In this study, to address these issues, we measured serum total and HMW adiponectins in Japanese men and post-menopausal women with type 2 diabetes, and investigated the relationship of each of the hormonal levels to BMD, bone metabolic markers, and the presence of vertebral fractures separately in each sex.

\section{Subjects and methods}

\section{Subjects}

The subjects in this study were 231 men and 170 postmenopausal women with type 2 diabetes (age; mean 59.6 and 66.7 respectively). We consecutively recruited subjects who visited Shimane University Hospital for an education, evaluation, or treatment of diabetes. All women had been without spontaneous menses for more than 1 year. Nobody had hepatic or renal dysfunction, disturbance of physical activity, or nutritional derangements that might cause changes in bone metabolism. Forty-one, 69, 24, and 34 men, as well as 45, 52, 35, and 20 women had been taking insulin treatment, sulfonylurea, metformin, and $\alpha$-glucosidase inhibitor respectively. Subjects treated with thiazolidinedione were excluded in this study. All subjects were free of drugs known to influence bone and calcium metabolism like vitamin D, bisphosphonate, and estrogen replacement therapy until the time of the present study. Sixty-three (27\%) men and $58(34 \%)$ women had diabetic retinopathy, while $132(57 \%)$ men and 97 $(57 \%)$ women had diabetic neuropathy. One hundred and three $(45 \%)$ men and $6(4 \%)$ women were current smokers, and $79(34 \%)$ men and $3(2 \%)$ women consumed over $1 \mathrm{U} /$ day of alcohol. This study was cross-sectional and approved by the ethical review board of our institution and complied with the Helsinki declaration. All subjects agreed to participate in the study and gave informed consent.

\section{Radiography}

Lateral X-ray films of the thoracic and lumbar spine were taken at the same week of the serum collection. The anterior, central, and posterior heights of each of the 13 vertebral bodies from Th4-L4 were measured. A vertebral fracture was diagnosed if at least one of three height measurements along the length of the same vertebrae had decreased by $>20 \%$ compared with the height of the nearest uncompressed vertebral body (32). Vertebral fractures were classified as follows; mild, a reduction of 20-25\%; moderate, 25-40\%; severe, more than $40 \%$. None of the subjects had a history of serious trauma.

\section{BMD and biochemical measurements}

BMD values of the total $(\mathrm{T})$, lumbar spine (L), femoral neck $(\mathrm{F})$, and one-third of the radius (1/3R) were measured by dual-energy X-ray absorptiometry (QDR4500; Hologic, Waltham, MA, USA). The same operator tested all the subjects during the study to eliminate operator discrepancies. The coefficients of variation (precision) of measurements of L-, F-, and 1/3R-BMD by our methods were $0.9,1.7$, and $1.9 \%$ respectively. $\mathrm{Z}$ score indicates deviation from the normal age- and sex-matched mean in S.D.

After overnight fasting, serum and first-void urine samples were collected. Biochemical markers were measured by standard biochemical methods. Hemoglobin $\mathrm{A}_{1 \mathrm{c}}\left(\mathrm{HbA}_{1 \mathrm{c}}\right)$ was determined by HPLC. Osteocalcin and urinary N-terminal cross-linked telopeptide of type-I collagen (uNTX) were measured by RIA and ELISA respectively, as previously described $(33,34)$. Serum HMW adiponectin levels were 
measured by an ELISA kit (Fujirebio, Tokyo, Japan) as indicated by the manufacturer. In brief, 96 wells of a microtiter plate were coated with anti-HMW adiponectin MAB. One hundred $\mu \mathrm{l}$ of serum samples diluted 1:441 was placed in each of the 96 wells. The MAB conjugated with HRP was used as the detecting antibody. Contents of wells were incubated for 30 min with tetramethylbenzipine. After the reaction was stopped, the absorbance was measured at $450 \mathrm{~nm}$. The coefficient of variation of measurements of HMW adiponectin was 2.0\%. Serum total adiponectin levels were measured by another ELISA kit (Otsuka Pharmaceuticals, Tokyo, Japan) as indicated by the manufacturer. In brief, after boiling serum samples in SDS buffer for $5 \mathrm{~min}$ to convert all adiponectin to a monomeric form, samples were analyzed with the ELISA system to determine total adiponectin in serum. The coefficient of variation of measurements of total adiponectin was $3.1 \%$.

\section{Statistical analysis}

Data were expressed as mean \pm s.D. Because serum total and HMW adiponectin levels showed markedly skewed distributions, logarithmic transformation (log) of these values were carried out before performing correlation and regression analysis. Statistical significance between two groups was determined using Student's $t$-test. Simple, multiple, and logistic regression analysis were performed using the statistical computer program StatView (Abacus Concepts, Berkeley, CA, USA). $P<0.05$ was considered to be significant.

\section{Results}

\section{Baseline characteristics of subjects}

Table 1 compares the male and post-menopausal female diabetic patients with respect to demographic and biochemical parameters and BMD. Patient age, serum total, and HMW adiponectins, osteocalcin, and uNTX were significantly lower in the males than in the females $(P<0.0001)$. On the other hand, body height, body weight, creatinine, absolute BMD at each site were significantly higher in the males than in the females $(P<0.0001)$.

\section{Relationship between each of serum total and HMW adiponectin levels versus BMD at each skeletal site and bone metabolic markers}

Our simple regression analysis showed that serum total and HMW adiponectin levels were significantly affected by age and body stature (Table 2). Thus, multiple regression analyses were performed between each of the serum adiponectin levels versus BMD at each skeletal site and bone metabolic markers adjusted for age, body mass index (BMI), as well as duration of diabetes, serum

Table 1 Baseline characteristics of subjects.

\begin{tabular}{|c|c|c|c|}
\hline & Men & Postmenopausal women & $\boldsymbol{P}$ \\
\hline Number of subjects & 231 & 170 & \\
\hline Age (years) & $59.6 \pm 13.3$ & $66.7 \pm 10.2$ & $<0.0001$ \\
\hline Diabetes duration (years) & $10.7 \pm 9.0$ & $12.3 \pm 9.9$ & 0.0619 \\
\hline Body height $(\mathrm{cm})$ & $165.9 \pm 6.7$ & $150.4 \pm 6.0$ & $<0.0001$ \\
\hline Body weight (kg) & $65.4 \pm 15.8$ & $55.4 \pm 11.0$ & $<0.0001$ \\
\hline BMI $\left(\mathrm{kg} / \mathrm{m}^{2}\right)$ & $23.6 \pm 4.7$ & $24.5 \pm 4.5$ & 0.0563 \\
\hline $\mathrm{HbA} 1 \mathrm{c}(\%)$ & $8.8 \pm 2.6$ & $8.4 \pm 2.4$ & 0.6918 \\
\hline Creatinine $(\mathrm{mg} / \mathrm{dl})$ & $0.80 \pm 0.18$ & $0.64 \pm 0.17$ & $<0.0001$ \\
\hline Total adiponectin $(\mu \mathrm{g} / \mathrm{ml})$ & $6.31 \pm 4.10$ & $8.80 \pm 5.85$ & $<0.0001$ \\
\hline HMW adiponectin $(\mu \mathrm{g} / \mathrm{ml})$ & $6.26 \pm 5.61$ & $9.08 \pm 7.32$ & $<0.0001$ \\
\hline Total BMD $\left(\mathrm{g} / \mathrm{cm}^{2}\right)$ & $1.080 \pm 0.113$ & $0.926 \pm 0.114$ & $<0.0001$ \\
\hline L2-4 BMD $\left(\mathrm{g} / \mathrm{cm}^{2}\right)$ & $1.044 \pm 0.189$ & $0.881 \pm 0.190$ & $<0.0001$ \\
\hline$T$ score & $-0.03 \pm 1.58$ & $-1.12 \pm 1.71$ & $<0.0001$ \\
\hline$Z$ score & $0.48 \pm 1.16$ & $0.62 \pm 1.22$ & 0.2724 \\
\hline F BMD $\left(\mathrm{g} / \mathrm{cm}^{2}\right)$ & $0.786 \pm 0.133$ & $0.643 \pm 0.131$ & $<0.0001$ \\
\hline$T$ score & $-0.62 \pm 1.05$ & $-1.33 \pm 1.20$ & $<0.0001$ \\
\hline$Z$ score & $0.33 \pm \overline{1.09}$ & $0.50 \pm 1.22$ & 0.1507 \\
\hline 1/3R BMD $\left(\mathrm{g} / \mathrm{cm}^{2}\right)$ & $0.712 \pm 0.069$ & $0.533 \pm 0.090$ & $<0.0001$ \\
\hline$T$ score & $-1.53 \pm 1.30$ & $-2.49 \pm 1.72$ & $<0.0001$ \\
\hline$Z$ score & $-0.59 \pm 1.15$ & $0.63 \pm 1.50$ & $<0.0001$ \\
\hline Osteocalcin (ng/ml) & $5.0 \pm 2 . \overline{4}$ & $7.2 \pm 2.9$ & $<0.0001$ \\
\hline uNTX (nMBCE/mM-Cr) & $32 . \overline{6} \pm 17.3$ & $54 . \overline{9} \pm 33.9$ & $<0.0001$ \\
\hline Vertebral fracture & $80(34.6 \%)$ & $52(30.6 \%)$ & 0.4567 \\
\hline Vertebral fracture (moderate or severe) & $19(8.2 \%)$ & $21(12.4 \%)$ & 0.2321 \\
\hline Osteopenia & $52(22.5 \%)$ & $69(40.5 \%)$ & 0.5635 \\
\hline Osteoporosis & $11(4.8 \%)$ & $31(18.2 \%)$ & 0.1140 \\
\hline
\end{tabular}

BMI, body mass index; FPG, fasting plasma glucose; $\mathrm{HbA}_{1 \mathrm{c}}$, hemoglobin $\mathrm{A}_{1 \mathrm{c}}$; HMW, high molecular weight; BMD, bone mineral density; L, lumbar; F, femoral neck; 1/3R, one-third of the radius; uNTX, urinary N-terminal cross-linked telopeptide of type-I collagen. 
Table 2 The correlations between serum adiponectin versus bone mineral density, bone metabolic marker, or other variables.

\begin{tabular}{|c|c|c|c|c|c|c|c|c|}
\hline & \multicolumn{4}{|c|}{ Men } & \multicolumn{4}{|c|}{ Postmenopausal women } \\
\hline & \multicolumn{2}{|c|}{ Log (total adiponectin) } & \multicolumn{2}{|c|}{ Log (HMW adiponectin) } & \multicolumn{2}{|c|}{ Log (total adiponectin) } & \multicolumn{2}{|c|}{ Log (HMW adiponectin) } \\
\hline & $r$ & $P$ & $r$ & $P$ & $r$ & $P$ & $r$ & $P$ \\
\hline Age & 0.292 & $<0.0001$ & 0.202 & 0.0021 & 0.323 & $<0.0001$ & 0.264 & 0.0005 \\
\hline $\begin{array}{l}\text { Duration of } \\
\text { diabetes }\end{array}$ & 0.203 & 0.0022 & 0.214 & 0.0012 & 0.310 & 0.0001 & 0.288 & 0.0003 \\
\hline Body height & -0.143 & 0.0295 & -0.074 & 0.2650 & -0.139 & 0.0711 & -0.108 & 0.1613 \\
\hline Body weight & -0.409 & $<0.0001$ & -0.229 & 0.0005 & -0.344 & $<0.0001$ & -0.322 & $<0.0001$ \\
\hline $\mathrm{BMI}$ & -0.432 & $<0.0001$ & -0.247 & 0.0001 & -0.314 & $<0.0001$ & -0.306 & $<0.0001$ \\
\hline $\mathrm{HbA} 1 \mathrm{c}$ & -0.102 & 0.1223 & -0.053 & 0.4251 & 0.077 & 0.3194 & 0.138 & 0.0743 \\
\hline Creatinine & 0.081 & 0.2190 & 0.053 & 0.4231 & 0.120 & 0.1178 & -0.034 & 0.6591 \\
\hline Total BMD & -0.301 & $<0.0001$ & -0.173 & 0.0145 & -0.264 & 0.0012 & -0.194 & 0.0195 \\
\hline L2-4 BMD & -0.220 & 0.0009 & -0.180 & 0.0072 & -0.205 & 0.0072 & -0.128 & 0.0954 \\
\hline$Z$ score & -0.163 & 0.0150 & -0.112 & 0.0949 & -0.085 & 0.2748 & -0.034 & 0.6601 \\
\hline F BMD & -0.326 & $<0.0001$ & -0.209 & 0.0019 & -0.293 & 0.0002 & -0.297 & 0.0001 \\
\hline$Z$ score & -0.211 & 0.0017 & -0.138 & 0.0411 & -0.184 & 0.0193 & -0.225 & 0.0041 \\
\hline 1/3R BMD & -0.252 & 0.0002 & -0.136 & 0.0477 & -0.286 & 0.0003 & -0.203 & 0.0110 \\
\hline$Z$ score & -0.041 & 0.5551 & -0.051 & 0.4629 & -0.099 & 0.2176 & -0.054 & 0.5052 \\
\hline Osteocalcin & 0.183 & 0.0083 & 0.084 & 0.2300 & 0.196 & 0.0156 & 0.051 & 0.5351 \\
\hline uNTX & 0.189 & 0.0045 & 0.107 & 0.1124 & 0.113 & 0.1540 & 0.177 & 0.0241 \\
\hline
\end{tabular}

$\mathrm{BMI}$, body mass index; $\mathrm{HbA}_{1 \mathrm{c}}$, hemoglobin $\mathrm{A}_{1 \mathrm{c}}$; $\mathrm{BMD}$, bone mineral density; L, lumbar; $\mathrm{F}$, femoral neck; 1/3R, one-third of the radius; uNTX, urinary $\mathrm{N}$-terminal cross-linked telopeptide of type-I collagen; HMW, high molecular weight.

creatinine, and $\mathrm{HbA}_{1 \mathrm{c}}$ (Table 3). In men, log (total adiponectin) was significantly and negatively correlated with T-, L-, and F-BMD $(P<0.05)$ and positively correlated with uNTX $(P<0.05)$, while $\log$ (HMW adiponectin) was only significantly and negatively correlated with L-BMD $(P<0.05)$. On the other hand, in post-menopausal women, neither $\log$ (total adiponectin) nor log (HMW adiponectin) were correlated with BMD at any site or any bone metabolic markers, except that $\log$ (total adiponectin) was significantly and positively correlated with osteocalcin $(P<0.01)$.

\section{Comparison of serum adiponectin levels and other variables between patients with and without vertebral fractures}

Next, we compared serum total and HMW adiponectin levels and other parameters between patients with and without vertebral fractures or with moderate or severe vertebral fractures (Table 4). The male and postmenopausal female patients with vertebral fractures or with moderate or severe vertebral fractures were significantly older $(P<0.05)$, shorter in height $(P<0.05)$, lower in absolute values of T-BMD $(P<0.05)$, and L-BMD $(P<0.05)$ than their counterparts without fractures. The post-menopausal female patients with vertebral fractures or with moderate or severe vertebral fractures had significantly lower absolute F-BMD and 1/3R-BMD than those without fractures $(P<0.05)$. The post-menopausal female patients with moderate or severe vertebral fractures had significantly lower $\mathrm{Z}$ score of F-BMD than those without fractures $(P<0.05)$. Serum total adiponectin level was significantly higher in men and postmenopausal women with vertebral fractures or with moderate or severe vertebral fractures than in those

Table 3 The correlations between serum adiponectin versus bone mineral density or bone metabolic marker.

\begin{tabular}{|c|c|c|c|c|c|c|c|c|}
\hline & \multicolumn{4}{|c|}{ Men } & \multicolumn{4}{|c|}{ Postmenopausal women } \\
\hline & \multicolumn{2}{|c|}{ Log (total adiponectin) } & \multicolumn{2}{|c|}{ Log (HMW adiponectin) } & \multicolumn{2}{|c|}{ Log (total adiponectin) } & \multicolumn{2}{|c|}{ Log (HMW adiponectin) } \\
\hline & $r$ & $P$ & $r$ & $P$ & $r$ & $P$ & $r$ & $P$ \\
\hline Total BMD & -0.165 & 0.0356 & -0.058 & 0.4293 & -0.118 & 0.1741 & -0.056 & 0.5156 \\
\hline L2-4 BMD & -0.187 & 0.0133 & -0.146 & 0.0382 & -0.071 & 0.4028 & -0.016 & 0.8517 \\
\hline F BMD & -0.136 & 0.0480 & -0.086 & 0.1763 & -0.096 & 0.2216 & -0.150 & 0.0557 \\
\hline 1/3R BMD & -0.129 & 0.0715 & -0.040 & 0.5475 & -0.098 & 0.2237 & -0.038 & 0.6383 \\
\hline Osteocalcin & 0.078 & 0.3020 & 0.025 & 0.7264 & 0.269 & 0.0033 & 0.105 & 0.2554 \\
\hline uNTX & 0.148 & 0.0489 & 0.074 & 0.2920 & 0.053 & 0.5293 & 0.075 & 0.3789 \\
\hline
\end{tabular}

Multiple regression analysis was performed between adiponectin versus $B M D$ at each skeletal site and bone markers adjusted for age, duration of diabetes, $\mathrm{BMI}$, creatinine, and $\mathrm{HbA1c}$. BMI, body mass index; $\mathrm{HbA}_{1 \mathrm{c}}$, hemoglobin $\mathrm{A}_{1 \mathrm{c}}$; BMD, bone mineral density; $\mathrm{L}$, lumbar; $\mathrm{F}$, femoral neck; $1 / 3 \mathrm{R}$, one-third of the radius; uNTX, urinary $\mathrm{N}$-terminal cross-linked telopeptide of type-I collagen; HMW, high molecular weight 
Table 4 Comparison of demographic and biochemical parameters including serum total and high molecular weight adiponectins between subjects with and without vertebral fractures.

\begin{tabular}{|c|c|c|c|c|c|c|c|c|c|c|}
\hline & \multicolumn{5}{|c|}{ Men } & \multicolumn{5}{|c|}{ Postmenopausal women } \\
\hline & \multirow[t]{2}{*}{$\begin{array}{l}\text { No vertebral } \\
\text { fracture }\end{array}$} & \multicolumn{2}{|c|}{ Vertebral fracture } & \multicolumn{2}{|c|}{$\begin{array}{l}\text { Moderate or severe } \\
\text { Vertebral fracture }\end{array}$} & \multirow[t]{2}{*}{$\begin{array}{l}\text { No vertebral } \\
\text { fracture }\end{array}$} & \multicolumn{2}{|c|}{ Vertebral fracture } & \multicolumn{2}{|c|}{$\begin{array}{l}\text { Moderate or severe } \\
\text { Vertebral fracture }\end{array}$} \\
\hline & & & $P$ & & $P$ & & & $P$ & & $P$ \\
\hline Number of patients & 151 & 80 & & 19 & & 118 & 52 & & 21 & \\
\hline Age & $57.8 \pm 13.3$ & $63.0 \pm 12.7$ & 0.0052 & $65.1 \pm 10.0$ & 0.0240 & $64.7 \pm 9.8$ & $71.3 \pm 9.8$ & $<0.0001$ & $74.2 \pm 10.3$ & 0.0001 \\
\hline Duration of diabetes & $10.2 \pm 9.2$ & $11.4 \pm 8.7$ & 0.3421 & $15.7 \pm 10.3$ & 0.0199 & $11.5 \pm 9.6$ & $14.2 \pm 10.3$ & 0.1172 & $16.0 \pm 10.3$ & 0.0717 \\
\hline Body height & $167 . \overline{1} \pm 6.5$ & $163 . \overline{8} \pm 6.7$ & 0.0004 & $163 . \overline{8} \pm 5.2$ & 0.0380 & $151 . \overline{3} \pm 5.7$ & $148 . \overline{3} \pm 6.0$ & 0.0029 & $145 . \overline{3} \pm 6.1$ & $<0.0001$ \\
\hline Body weight & $67.0 \pm 17.3$ & $62.3 \pm 12.0$ & 0.0339 & $63.1 \pm 7.6$ & 0.3352 & $56.2 \pm 10.8$ & $53.6 \pm 11.5$ & 0.1545 & $51.1 \pm 13.8$ & 0.0658 \\
\hline BMI & $23.9 \pm 5.2$ & $23.1 \pm 3.6$ & 0.2795 & $23.5 \pm 2.7$ & 0.7684 & $24.5 \pm 4.3$ & $24.3 \pm 5.0$ & 0.8000 & $24.2 \pm 6.0$ & 0.7546 \\
\hline $\mathrm{HbA1c}$ & $8.9 \pm 2.8$ & $8.8 \pm 2.2$ & 0.7644 & $8.5 \pm 1.9$ & 0.5694 & $8.8 \pm 2.3$ & $8.8 \pm 2.6$ & 0.9720 & $8.8 \pm 2.5$ & 0.9919 \\
\hline Creatinine & $0.79 \pm 0.18$ & $0.80 \pm 0.19$ & 0.8403 & $0.83 \pm 0.23$ & 0.4664 & $0.63 \pm 0.17$ & $0.68 \pm 0.17$ & 0.0709 & $0.65 \pm 0.14$ & 0.5123 \\
\hline Total adiponectin & $5.84 \pm 3.78$ & $7.19 \pm 4.55$ & 0.0165 & $8.39 \pm 4.50$ & 0.0073 & $8.04 \pm 4.98$ & $10.53 \pm 7.22$ & 0.0101 & $10.82 \pm 7.51$ & 0.0353 \\
\hline HMW adiponectin & $5.88 \pm 4.86$ & $6.97 \pm 6.77$ & 0.1581 & $9.72 \pm 7.73$ & 0.0030 & $8.38 \pm 6.80$ & $10.67 \pm 8.24$ & 0.0599 & $10.67 \pm 8.71$ & 0.1839 \\
\hline Total BMD & $1.094 \pm 0.115$ & $1.053 \pm 0.103$ & 0.0137 & $1.030 \pm 0.103$ & 0.0317 & $0.944 \pm 0.113$ & $0.882 \pm 0.103$ & 0.0021 & $0.853 \pm 0.093$ & 0.0035 \\
\hline L2-4 BMD & $1.063 \pm 0.203$ & $1.009 \pm 0.154$ & 0.0432 & $0.966 \pm 0.153$ & 0.0464 & $0.902 \pm 0.172$ & $0.832 \pm 0.219$ & 0.0246 & $0.767 \pm 0.272$ & 0.0037 \\
\hline$Z$ score & $0.56 \pm 1.26$ & $0.33 \pm 0.93$ & 0.1444 & $0.07 \pm 0.87$ & 0.1004 & $0.70 \pm 1.14$ & $0.45 \pm 1.40$ & 0.2234 & $0.11 \pm 1.84$ & 0.0556 \\
\hline F BMD & $0.798 \pm 0.137$ & $0.764 \pm 0.122$ & 0.0764 & $0.74 \overline{5} \pm 0.107$ & 0.1104 & $0.661 \pm 0.124$ & $0.603 \pm 0.138$ & 0.0085 & $0.537 \pm 0.162$ & 0.0003 \\
\hline$Z$ score & $0.38 \pm 1.17$ & $0.25 \pm 0.92$ & 0.4152 & $0.19 \pm 0.91$ & 0.5097 & $0.58 \pm 1.18$ & $0.31 \pm 1.31$ & 0.2010 & $-0.16 \pm 1.70$ & 0.0224 \\
\hline 1/3R BMD & $0.716 \pm 0.072$ & $0.704 \pm 0.063$ & 0.2191 & $0.702 \pm 0.069$ & 0.4166 & $0.544 \pm 0.090$ & $0.509 \pm 0.087$ & 0.0292 & $0.497 \pm 0.077$ & 0.0432 \\
\hline$Z$ score & $-0.56 \pm 1.18$ & $-0.64 \pm 1.09$ & 0.6528 & $-0.47 \pm 0.99$ & 0.7548 & $0.64 \pm 1.57$ & $0.61 \pm 1.33$ & 0.9230 & $0.77 \pm 1.42$ & 0.7471 \\
\hline Osteocalcin & $5.1 \pm 2 . \overline{5}$ & $4.8 \pm 2.3$ & 0.4558 & $5.3 \pm 3.0$ & 0.7760 & $7.1 \pm 3.0$ & $7.2 \pm 2.8$ & 0.8527 & $6.5 \pm 2.4$ & 0.3940 \\
\hline uNTX & $32.4 \pm 18.0$ & $33.0 \pm 16.2$ & 0.7975 & $34.5 \pm 20.1$ & 0.6411 & $52.4 \pm 28.4$ & $60.5 \pm 43.5$ & 0.1568 & $60.3 \pm 42.5$ & 0.2945 \\
\hline
\end{tabular}

BMI, body mass index; $\mathrm{HbA}_{1 c}$, hemoglobin $\mathrm{A}_{1 \mathrm{c}}$; $\mathrm{HMW}$, high molecular weight; $\mathrm{BMD}$, bone mineral density; L, lumbar; $\mathrm{F}$, femoral neck; 1/3R, one-third of the radius; uNTX, urinary N-terminal cross-linked telopeptide of type-I collagen. 
without fractures $(P<0.05)$. Serum HMW adiponectin was significantly higher in men with moderate or severe vertebral fractures than in those without fractures $(P<0.01)$. No difference was found in serum osteocalcin or uNTX between those with and without fractures.

When multivariate logistic regression analysis was performed with the presence of vertebral fractures as a dependent variable and serum total and HMW adiponectin levels, bone markers, and absolute BMD values at each site adjusted for age, BMI, duration of diabetes, serum creatinine, and $\mathrm{HbA}_{1 \mathrm{c}}$ as independent variables (Table 5), total adiponectin in men was selected as an index affecting the presence of vertebral fractures $(P<0.05)$, as well as T-BMD and L-BMD $(P<0.05)$. Moreover, serum total and HMW adiponectin levels as well as T-BMD and L-BMD were associated with the presence of moderate or severe vertebral fractures in men $(P<0.05)$ (Table 5). By contrast, no parameters were selected in post-menopausal women.

\section{Discussion}

In this study, we found that serum total adiponectin level was negatively correlated with T-, L-, and F-BMD and positively with UNTX, and serum HMW adiponectin level was negatively correlated with L-BMD in diabetic men, while it was positively correlated with serum osteocalcin level, but not with uNTX or BMD at any site in post-menopausal women. Logistic regression analysis showed that total and HMW adiponectin were significantly and positively associated with the presence of vertebral fractures in type 2 diabetic men, suggesting that they are not only correlated with BMD or UNTX but also are useful markers for assessing the risk of vertebral fractures specifically in diabetic males.

Several studies investigated the relationship between serum adiponectin and BMD in subjects without diabetes. In non-diabetic men, Oh et al. showed that serum adiponectin level had no significant correlation with BMD in 80 adults (19). By contrast, Peng et al. showed that the hormonal level was significantly and negatively correlated with T-, L-, and F-BMD in 232 men (15). Moreover, Michaëlsson et al. recently showed that a negative association between adiponectin and BMD was found in two cohorts, one recruited 441 men and another 507 men (21). Our finding was consistent with the latter two reports. In non-diabetic women, serum adiponectin level was reported to be negatively correlated with BMD (12-14), while other studies showed no significant correlation (16-18). Our finding that the hormone level was not significantly correlated with BMD at any site in diabetic women seems to be in accordance with the latter observation. By contrast, few studies were performed in diabetic subjects with regard to the relationship between serum adiponectin level and BMD. Lenchik et al. showed that after adjusting for age, gender, race, smoking, and diabetes status, serum adiponectin was inversely associated with BMD in 38 women and 42 men ( $86 \%$ with type 2 diabetes) (11). Tamura et al. showed that there were a significant positive correlation between serum adiponectin level and $\mathrm{Z}$ score at R-BMD, but not at L- or F-BMD in 40 Japanese patients ( 28 men and 12 women) with type 2 diabetes (20). Although they investigated men and women together, some adiponectin variability is suggested to be sex related: serum total and HMW adiponectins have been reported to be higher in post-menopausal women

Table 5 Associations between the presence of vertebral fractures and serum adiponectin.

\begin{tabular}{lllll}
\hline & \multicolumn{2}{c}{ Men } & & Postmenopausal women \\
\cline { 2 - 3 } \cline { 5 - 5 } & OR $(95 \% \mathrm{Cl})$ & $P$ & OR $(95 \% \mathrm{Cl})$ & $P$ \\
\hline Presence of vertebral fractures & & & $1.341(0.916-1.964)$ & 0.1310 \\
$\quad$ Total adiponectin & $1.396(1.020-1.911)$ & 0.0371 & $1.214(0.828-1.780)$ & 0.3208 \\
HMW adiponectin & $1.199(0.895-1.608)$ & 0.2235 & $0.743(0.469-1.178)$ & 0.2061 \\
Total BMD & $0.700(0.501-0.979)$ & 0.0372 & $0.835(0.553-1.262)$ & 0.3922 \\
L2-4 BMD & $0.709(0.522-0.963)$ & 0.0280 & $0.826(0.523-1.305)$ & 0.4136 \\
F BMD & $0.831(0.593-1.166)$ & 0.2846 & $1.013(0.631-1.623)$ & 0.9588 \\
1/3R BMD & $1.011(0.728-1.403)$ & 0.9496 & $0.957(0.626-1.464)$ & 0.8405 \\
Osteocalcin & $0.844(0.606-1.176)$ & 0.3163 & $1.233(0.831-1.829)$ & 0.2976 \\
uNTX & $0.998(0.743-1.342)$ & 0.9908 & & \\
Presence of moderate or severe vertebral fractures & & & $1.395(0.824-2.360)$ & 0.2150 \\
Total adiponectin & $1.709(1.048-2.787)$ & 0.0316 & $1.150(0.661-2.001)$ & 0.6208 \\
HMW adiponectin & $1.810(1.112-2.946)$ & 0.0169 & $0.473(0.198-1.129)$ & 0.0918 \\
Total BMD & $0.527(0.296-0.938)$ & 0.0295 & $0.538(0.259-1.114)$ & 0.0952 \\
L2-4 BMD & $0.527(0.303-0.916)$ & 0.0233 & $0.551(0.262-1.157)$ & 0.1152 \\
F BMD & $0.719(0.410-1.259)$ & 0.2479 & $0.950(0.434-2.082)$ & 0.8984 \\
1/3R BMD & $1.165(0.692-1.962)$ & 0.5655 & $0.762(0.389-1.494)$ & 0.4287 \\
Osteocalcin & $1.096(0.666-1.804)$ & 0.7173 & $1.288(0.692-2.396)$ & 0.4244 \\
uNTX & $1.115(0.682-1.823)$ & 0.6641 & & \\
\hline
\end{tabular}

Multivariate logistic regression analysis was performed with the presence of vertebral fractures as a dependent variable and each level of adiponectin adjusted for age, duration of diabetes, BMI, creatinine, and HbA1c as independent variables. HMW, high molecular weight; BMD, bone mineral density; L, lumbar; F, femoral neck; 1/3R, one-third of the radius; uNTX, urinary N-terminal cross-linked telopeptide of type-I collagen; OR, odds ratio; Cl, confidential intervals. Unit of change; standard deviation per increase. 
than in men $(29,30)$. Therefore, it would be more suitable to perform clinical studies on adiponectin after separating between men and women in order to avoid such sexrelated differences. In the present study, we investigated correlation between adiponectin and BMD in a larger population of each gender. Our findings of significant negative correlation between total and HMW adiponectin and BMD in the diabetic males seem to accord with those of Lenchik et al.

To our knowledge, the present study is the first one that investigated the association between the difference in molecular sizes of adiponectin versus BMD, bone metabolic markers, and the presence of vertebral fractures. We found that serum total adiponectin level was associated with BMD, uNTX, and the presence of vertebral fractures more potently than HMW adiponectin, while both serum total and HMW adiponectin were associated with the presence of moderate or severe vertebral fractures. However, little is known about the distribution and function of each adiponectin isoform in the bone microenvironment, and further studies are needed to clarify the significance of adiponectin molecular sizes in bone metabolism.

Adiponectin has recently attracted widespread attention, especially in the diabetes field, due to their beneficial anti-diabetic and anti-atherosclerotic effects. We and other researchers have also shown that adiponectin stimulates osteoblastogenesis and bone formation in cultured osteoblasts $(9,10,35)$. Luo et al. have shown that adiponectin regulated bone turnover via enhancing the receptor activator of nuclear factor- $\mathrm{KB}$ ligand (RANKL) expression and suppressing its decoy receptor, osteoprotegerin (OPG) (36). Thus, agents that are able to increase circulating adiponectin may improve not only energy metabolism or atherosclerosis but also bone metabolism. Indeed, in clinical studies, several researchers documented the significant relationship between serum adiponectin and bone metabolic markers in normal subjects. Peng et al. showed that serum adiponectin was positively correlated with BAP and uNTX in 232 men after adjustment for age and fat mass (15). Richard et al. showed that serum adiponectin was positively associated with osteocalcin in 1208 women after adjustment for age, BMI, central fat mass, insulin levels, smoking, menopause, and HRT status (12). The present study also showed that total adiponectin level was positively associated with uNTX and osteocalcin in the diabetic males and post-menopausal females respectively. These clinical observations seem to accord with a recent in vitro study reporting that osteocalcin increases adiponectin expression in adipocytes (37). Taken together, both experimental and clinical studies suggest that adiponectin could accelerate bone turnover and might improve low bone turnover-associated bone fragility that is typically seen in diabetic patients (38).

The present study indicated a negative correlation between serum adiponectin level and BMD in diabetic men. This finding seems a little contradictory, given that we and other researchers have shown the stimulatory action of adiponectin on osteoblastogenesis and bone formation by in vivo and in vitro experiments $(9,10,35)$. One possible explanation is that serum adiponectin level in subjects with osteoporosis reactively elevates through its up-regulated synthesis and secretion, in order to protect bone from osteopenia. This explanation is supported by the observation that serum OPG level is also negatively correlated with $\mathrm{BMD}$, although it acts as a decoy receptor for RANKL and protects bone from osteopenia through inhibiting osteoclastic activities (39).

This study has some limitations. First, the sample size was not large enough to make definite conclusions. Second, we analyzed only subjects who visited Shimane University Hospital, a tertiary center, for the evaluation or treatment of diabetes mellitus and osteoporosis. Therefore, the patients enrolled in this study might have relatively severe states of the disorders and might not be representative of Japanese men and postmenopausal women with the disorders. Consequently, assessment of larger numbers of patients is necessary to determine the usefulness of serum adiponectin levels for predicting the risk of vertebral fractures. Third, vertebral fracture rates in the present populations (34.6\% in male and $30.6 \%$ in female) seem to be higher than those observed in Western counterparts. However, we found the similar fracture rate $(31.6 \%)$ in 193 non-diabetic post-menopausal women in a previous study (40), and comparison of vertebral fracture rates between one Japanese and two European cohorts show that Japanese have a higher fracture rate than Europeans (41-43). Fourth, BMI in the present populations (mean; 23.6 in male and 24.5 in female) were lower than those observed in Western people. It is because the capacity of insulin secretion and the degree of obesity in Asian populations are known to be different from Western people (44). Therefore, further studies are needed to examine whether or not our findings are also seen in Western populations. Fifth, the significant difference in age between men and women found in this study could reduce the significance of comparisons because adiponectin is markedly influenced by age. Finally, a previous genetic study has shown that low serum adiponectin levels might be influenced by genetic factors (45), and thus it is possible that genes for adiponectin may predetermine its serum levels independent of bone status, and the hormone levels may not reflect the bone microenvironment. On the contrary, strengths of our study are that the number of subjects was relatively larger than those of previous studies in type 2 diabetes, and that we measured both the total and HMW adiponectins and examined their relationship with bone parameters in separate genders. We also for the first time showed the association between serum adiponectin levels and the presence of vertebral fractures. 
In conclusion, the present study showed that serum adiponectin was associated with BMD, uNTX, and the presence of vertebral fractures in men, and that serum adiponectin was positively associated with serum osteocalcin in post-menopausal women. These findings suggest that serum adiponectin was involved in bone metabolism and that the hormonal level may be as efficient as BMD in assessing the risk of vertebral fractures in diabetic males.

\section{Declaration of interest}

The authors declare that there is no conflict of interest that could be perceived as prejudicing the impartiality of the research reported.

\section{Funding}

This study was supported by a grant from Japan Osteoporosis Society for Kanazawa I.

\section{References}

1 Lim S, Joung H, Shin CS, Lee HK, Kim KS, Shin EK, Kim HY, Lim MK \& Cho SI. Body composition changes with age have gender-specific impacts on bone mineral density. Bone 200435 792-798.

2 Felson DT, Zhang Y, Hannan MT \& Anderson JJ. Effects of weight. and body mass index on bone mineral density in men and women. Journal of Bone and Mineral Research 19938 567-573.

3 Glauber HS, Vollmer WM, Nevitt MC, Ensrud KE \& Orwoll ES. Body weight versus body fat distribution, adiposity, and frame size as predictors of bone density. Journal of Clinical Endocrinology and Metabolism 199580 1118-1123.

4 Maeda K, Okubo K, Shimomura I, Mizuno K, Matsuzawa Y \& Matsubara K. Analysis of an expression profile of genes in the human adipose tissue. Gene 1997190 227-235.

5 Weyer C, Funahashi T, Tanaka S, Hotta K, Matsuzawa Y, Pratley RE \& Tataranni PA. Hypoadiponectemia in obesity and type 2 diabetes: close association with insulin resistance and hyperinsulinemia. Journal of Clinical Endocrinology and Metabolism 200186 1930-1935.

6 Arita Y, Kihara S, Ouchi N, Takahashi M, Maeda K, Miyagawa J, Hotta K, Shimomura I, Nakamura T, Miyaoka K, Kuriyama H, Nishida M, Yamashita S, Okubo K, Matsubara K, Muraguchi M, Ohmoto Y, Funahashi T \& Matsuzawa Y. Paradoxical decrease of an adipose-specific protein, adiponectin, in obesity. Biochemical and Biophysical Research Communications 1999257 79-83.

7 Combs TP, Berg AH, Obici S, Scherer PE \& Rossetti L. Endogenous glucose production is inhibited by the adipose-derived protein Acrp30. Journal of Clinical Investigation 2001108 1875-1881.

8 Berg AH, Combs TP, Du X, Brownlee M \& Scherer PE. The adipocyte-secreted protein Acrp30 enhances hepatic insulin action. Nature Medicine 20017 947-953.

9 Kanazawa I, Yamaguchi T, Yano S, Yamauchi M, Yamamoto M \& Sugimoto T. Adiponectin and AMP kinase activator stimulate proliferation, differentiation, and mineralization of osteoblastic MC3T3-E1 cells. BMC Cell Biology 20078 51-62.

10 Berner HS, Lyngstadaas SP, Spahr A, Monjo M, Thommesen L, Drevon CA, Syversen U \& Reseland JE. Adiponectin and its receptors are expressed in bone-forming cells. Bone 200435 842-849.

11 Lenchik L, Register TC, Hsu FC, Lohman K, Nicklas BJ, Freedman BI, Langefeld CD, Carr JJ \& Bowden DW. Adiponectin as a novel determinant of bone mineral density and visceral fat. Bone $200333646-651$.
12 Richards JB, Valdes AM, Burling K, Perks UC \& Spector TD. Serum adiponectin and bone mineral density in women. Journal of Clinical Endocrinology and Metabolism 200792 1517-1523.

13 Jürimäe J \& Jürimäe T. Adiponectin is a predictor of bone mineral density in middle-aged premenopausal women. Osteoporosis International 200718 1253-1259.

14 Jürimäe J, Rembel K, Jürimäe T \& Rehand M. Adiponectin is associated with bone mineral density in perimenopausal women. Hormone Metabolic Research 200537 297-302.

15 Peng XD, Xie H, Zhao Q, Wu XP, Sun ZQ \& Liao EY. Relationships between serum adiponectin, leptin, resistin, visfatin levels and bone mineral density, and bone biochemical markers in Chinese men. Clinica Chimica Acta $2008 \mathbf{3 8 7} 31-35$.

16 Kontogianni M, Dafni UG, Routsias J \& Skopouli FN. Blood leptin and adiponectin as possible mediators of the relation between fat mass and BMD in perimenopausal women. Journal of Bone and Mineral Research 200419 546-551.

17 Huang KC, Cheng WC, Yen RF, Tsai KS, Tai TY \& Yang WS. Lack of independent relationship between plasma adiponectin, leptin levels and bone density in nondiabetic female adolescents. Clinical Endocrinology $200461204-208$.

18 Jürimäe J \& Jürimäe T. Plasma adiponectin concentration in healty pre- and postmenopausal women: relationship with body composition, bone mineral, and metabolic cariables. American Journal of Physiology. Endocrinology and Metabolism 2007293 E42-E47.

19 Oh KW, Lee WY, Rhee EJ, Baek KH, Yoon KH, Kang MI, Yun EJ, Park CY, Ihm SH, Choi MG, Yoo HJ \& Park SW. The relationship between serum resistin, leptin, adiponectin, ghrelin levels and bone mineral density in middle-aged men. Clinical Endocrinology 200563 131-138.

20 Tamura T, Yoneda M, Yamane K, Nakanishi S, Nakashima R, Okubo M \& Kohno N. Serum leptin and adiponectin are positively associated with bone mineral density at the distal radius in patients with type 2 diabetes mellitus. Metabolism $2007 \mathbf{5 6}$ 623-628.

21 Michaëlsson K, Lind L, Frystyk J, Flyvbjerg A, Gedeborg R, Berne C, Zethelius B, Mallmin H, Söderberg S \& Melhus H. Serum adiponectin in elderly men dose not correlate with fracture risk. Journal of Clinical Endocrinology and Metabolism 200893 4041-4047.

22 Schwartz AV, Sellmeyer DE, Ensrud KE, Cauley JA, Tabor HK, Schreiner PJ, Jamal SA, Black DM \& Cummings SR. Older women with diabetes have an increased risk of fracture: a prospective study. Journal of Clinical Endocrinology and Metabolism 200186 32-38.

23 Vestergaard P, Rejnmark L \& Mosekilde L. Relative fracture risk in patients with diabetes mellitus, and the impact of insulin and oral antidiabetic medication on relative fracture risk. Diabetologia 2005 48 1292-1299.

24 Nicodemus KK \& Folsom AR. lowa Women's Health Study. Type 1 and type 2 diabetes and incident hip fractures in postmenopausal women. Diabetes Care 200124 1192-1197.

25 Strotmeyer ES, Cauley JA, Schwartz AV, Nevitt MC, Resnick HE, Bauer DC, Tylavsky FA, de Rekeneire N, Harris TB \& Newman AB. Nontraumatic fracture risk with diabetes mellitus and impaired fasting glucose in older white and black adults: the health, aging, and body composition study. Archives of Internal Medicine 2005 $1651612-1617$.

26 Yamamoto M, Yamaguchi T, Yamauchi M, Kaji H \& Sugimoto T. Bone mineral density is not sensitive enough to assess the risk of vertebral fractures in type 2 diabetic women. Calcified Tissue International 200780 353-358.

27 Kanazawa I, Yamaguchi T, Yamamoto M, Yamauchi M, Yano S \& Sugimoto T. Serum insulin-like growth factor-I is associated with the presence of vertebral fractures in postmonopausal women with type 2 diabetes mellitus. Osteoporosis International 200718 1675-1681.

28 Yamamoto M, Yamaguchi T, Yamauchi M, Yano S \& Sugimoto T. Serum pentosidine levels are positively associated with the presence of vertebral fractures in postmenopausal women with type 2 diabetes. Journal of Clinical Endocrinology and Metabolism 200893 1013-1019. 
29 Pajvani UB, Hawkins M, Combs TP, Rajala MW, Doebber T, Berger JP, Wagner JA, Wu M, Knopps A, Xiang AH, Utzschneider KM, Kahn SE, Olefsky JM, Buchanan TA \& Scherer PE. Complex distribution, not absolute amount of adiponectin, correlates with thiazolidinedionemediated improvement in insulin sensitivity. Journal of Biological Chemistry $200427912152-12162$.

30 Waki H, Yamauchi T, Kamon J, Ito Y, Uchida S, Kita S, Hara K, Hada Y, Vasseur F, Froguel P, Kimura S, Nagai R \& Kadowaki T. Impaired multimerization of human adiponectin mutants associated with diabetes: molecular structure and multimer formation of adiponectin. Journal of Biological Chemistry 2003 $27840352-40363$.

31 Tsao TS, Tomas E, Murrey HE, Hug C, Lee DH, Ruderman NB, Heuser JE \& Lodish HF. Role of disulfide bonds in Acrp30/adiponectin structure and signaling specificity: different oligomers activate different signal transduction pathways. Journal of Biological Chemistry $200327850810-50817$.

32 Genant HK, Jergas M, Palermo L, Nevitt M, Valentin RS, Black D \& Cummings SR. Comparison of semiquantitative visual and quantitative morphometric assessment of prevalent and incident vertebral fractures in osteoporosis. The Study of Osteoporotic Fractures Research Group. Journal of Bone and Mineral Research $200611984-996$.

33 Sugimoto T, Nishiyama K, Kuribayashi F \& Chihara K. Serum levels of insulin-like growth factor (IGF) I, IGF-binding protein (IGFBP)-2, and IGFBP-3 in osteoporotic patients with and without spinal fractures. Journal of Bone and Mineral Research 199712 $1272-1279$.

34 Kaji H, Nomura R, Yamauchi M, Chihara K \& Sugimoto T. The usefulness of bone metabolic indices for the prediction of changes in bone mineral density after parathyroidectomy in patients with primary hyperparathyroidism. Hormone Metabolic Research 2006 38 411-416.

35 Oshima K, Nampei A, Matsuda M, Iwaki M, Fukuhara A, Hashimoto J, Yoshikawa H \& Shimomura I. Adiponectin increases bone mass by suppressing osteoclast and activating osteoblast. Biochemical and Biophysical Research Communications 2005331 520-526.

36 Luo XH, Guo LJ, Xie H, Yuan LQ, Wu XP, Zhou HD \& Liao EY. Adiponectin stimulates RANKL and inhibits OPG expression in human osteoblasts through the MAPK signaling pathway. Journal of Bone and Mineral Research 200621 1648-1656.
37 Lee NK, Sowa H, Hinoi E, Ferron M, Ahn JD, Confavreux C, Dacquin R, Mee PJ, McKee MD, Jung DY, Zhang Z, Kim JK, Mauvais-Jarvis F, Ducy P \& Karsenty G. Endocrine regulation of energy metabolism by the skeleton. Cell $2007130456-469$.

38 Saito M, Fujii K, Mori Y \& Marumo K. Role of collagen enzymatic and glycation induced cross-links as a determinant of bone quality in spontaneously diabetic WBN/Kob rats. Osteoporosis International $2006171514-1523$.

39 Samelson EJ, Broe KE, Demissie S, Beck TJ, Karasik D, Kathiresan S \& Kiel DP. Increased plasma osteoprotegerin concentrations are associated with indices of bone strength of the hip. Journal of Clinical Endocrinology and Metabolism 200893 1789-1795.

40 Yamaguchi T, Kanatani M, Yamauchi M, Kaji H, Sugishita T, Baylink DJ, Mohan S, Chihara K \& Sugimoto T. Serum levels of insulin-like growth factor (IGF); IGF-binding proteins-3, -4, and -5 ; and their relationships to bone mineral density and the risk of vertebral fractures in postmenopausal women. Calcified Tissue International $2006 \mathbf{7 8} 18-24$.

41 Fujiwara S, Kasagi F, Masunari N, Naito K, Suzuki G \& Fukunaga M. Fracture prediction from bone mineral density in Japanese men and women. Journal of Bone and Mineral Research 200318 1547-1553.

42 The European Prospective Osteoporosis Study (EPOS) Group. Incidence of vertebral fracture in Europe: results from the European Prospective Osteoporosis Study (EPOS). Journal of Bone and Mineral Research 200217 716-724.

43 Van der Klift M, De Laet CE, McCloskey EV, Hofman A \& Pols HA. The incidence of vertebral fractures in men and women: the Rotterdam Study. Journal of Bone and Mineral Research 200217 1051-1056.

44 Fujimoto WY. Overview of non-insulin-dependent diabetes mellitus (NIDDM) in different population groups. Diabetic Medicine 199613 S7-10.

45 Hara K, Boutin P, Mori Y, Tobe K, Dina C, Yasuda K, Yamauchi T, Otabe S, Okada T, Eto K, Kadowaki H, Hagura R, Akanuma Y, Yazaki Y, Nagai R, Taniyama M, Matsubara K, Yoda M, Nakano Y, Kimura S, Tomita M, Kimura S, Ito C, Froguel P \& Kadowaki T. Genetic cariation in the gene encoding adiponectin in associated with an increased risk of type 2 diabetes in the Japanese population. Diabetes $2002 \mathbf{5 1} 536-540$.

Received 4 November 2008

Accepted 5 November 2008 